\title{
Gut-associated Lymphoid Tissue (GALT) Carcinoma or Dome Carcinoma?
}

\author{
CARLOS A. RUBIO ${ }^{1}$ and PETER T. SCHMIDT ${ }^{2}$ \\ ${ }^{1}$ Department of Pathology, Karolinska Institute and University Hospital, Stockholm, Sweden; \\ ${ }^{2}$ Department of Medicine, Center for Digestive Diseases, \\ Karolinska Institute and University Hospital, Stockholm, Sweden
}

\begin{abstract}
Background/Aim: The vast majority of colorectal carcinomas (CRCs) evolve from mucosa not associated to lymphoid tissues aggregates via the adenomacarcinoma sequence or via the serrated pathway. Rarely CRCs evolve from gut mucosa associated to lymphoid tissue (GALT). Materials and Methods: Based on the presence of a circumscribed elevation in the colorectal mucosa, GALT carcinomas are also referred to as dome carcinomas (DC). Descriptions of the surface mucosa covering 21 GALT-CRCs appearing in pathological reports were reviewed. Results: Three of the 21 GALT-CRCs fulfilled the criteria of dome carcinoma. Of the remaining 18 GALT-CRCs, nine were described as polypoid lesions, five as plaque-like lesions, two as sessile elevated lesions or mass, one as ulcerated and one as histological finding. Hence, only $14.3 \%(n=3)$ of the 21 GALT-CRCs displayed a dome configuration, whereas the majority, $85.7 \%(n=18)$, exhibited structures other than dome shapes at gross or at histologic examination. Conclusion: It becomes apparent that by using "dome" in addressing carcinomas in the colorectal mucosa, many cases of GALT carcinomas might be overlooked. Another drawback of using the "dome" nomenclature is that dome-like outlines may be detected in small metastatic tumors in the submucosa or in small colorectal carcinomas not arising from GALT mucosa. Instead, by using "GALT carcinoma", that is the histologic diagnosis in addressing these neoplasias, all cases of GALT-CRCs will be included.
\end{abstract}

Correspondence to: Carlos A. Rubio, MD, $\mathrm{PhD}$, Gastrointestinal and Liver Pathology Research Laboratory, Department of Pathology, Karolinska Institute and University Hospital, 17176, Stockholm, Sweden. Tel: +46 851774527, Fax: +46 851774524, e-mail: Carlos.Rubio@ki.se

Key Words: Colorectal cancer, gut-associated lymphoid tissue, dome carcinoma.
The colorectal mucosa may be divided into two quantitatively, structurally and functionally different mucosal fractions. One fraction, associated with microscopically tiny lymphoid tissue aggregates, is called gut-associated lymphoid tissue (GALT) mucosa (1). The GALT mucosa is covered with a single layer of cells with few or no goblet cells. This single layer of cells display broad invaginations (microfolds) that amplify the cell surface forming intraepithelial pockets. Electron microscopy shows clear-cut micro-folds or micro-ridges that give the cell its name, namely $\mathrm{M}$ cells. The function of the $\mathrm{M}$ cells is to absorb luminal antigens, macromolecules and microorganisms via clathrin-mediated endocytosis (1) and haul them into the underlying collection of gut-indigenous, thymus-independent lymphoid tissue for immediate immunological processing. The constellation $\mathrm{M}$ cells-lymphoid tissue builds a lymphoepithelial immunological cross-talk unit, a relay complex for antigen-gut recognition. The frequency of the lymphoglandular complexes (that is GALT mucosa) increases from the proximal to the distal colon, being highest in the rectum (2). In colons with inflammatory bowel disease, the frequency of GALT complexes was significantly higher (mean $0.32 / \mathrm{mm}$ muscularis mucosae) (2). Nasciembeni et al. also studied the lymphoid aggregate density in the colon. They found a mean of 0.3 lymphoid aggregates $/ \mathrm{cm}^{2}$ in 77 consecutive colectomies from patients with Crohn's disease and a mean of 2.7 lymphoid aggregates $/ \mathrm{cm}^{2}$ in the mucosa of patients with colorectal cancer (3). Multiple lymphoid aggregates are newly formed in the submucosa and deeper layers in Crohn's colitis (4).

The other mucosal fraction, comprehending the vast majority of the colorectal mucosa, is not associated to lymphoid tissue aggregates. This GALT-free mucosa is built with mucus-producing goblet cells and columnar cells furnished with regular microvilli roofed by the extracellular glycoprotein glycocalix. The function of this huge mucosal fraction is to protect underlying structures and absorb fluids, vitamins and some nutrients.

It is generally accepted that the overwhelming majority of colorectal carcinomas (CRCs), the third most frequent cancer 
Table I. Descriptions of the luminal configuration covering 21 gut-associated lymphoid tissue (GALT) carcinomas appearing in published reports in the literature.

\begin{tabular}{|c|c|c|c|c|}
\hline Authors (reference) & Year & No. cases & No. GALT-CRCs & Description of surface mucosa \\
\hline Rubio (8) & 1984 & One & One & Irregular plaque-like lesion \\
\hline De Petris et al. (9) & 1999 & One & Two & One dome, one ulcerated \\
\hline Jass et al. (10) & 2000 & One & One & Dome \\
\hline \multirow[t]{2}{*}{ Clouston, Clouston, Jass (11) } & 2002 & Two & One (Case 1) & Polypoid lesion \\
\hline & & & One (Case 2) & Polypoid lesion \\
\hline Rubio and Talbot (12) & 2002 & One & One & Polypoid lesion \\
\hline \multirow[t]{2}{*}{ Stewart et al. (13) } & 2008 & Two & One (Case 1) & Polypoid lesion \\
\hline & & & One (Case 2) & Plaque-like lesion \\
\hline \multirow[t]{2}{*}{ Asmussen, Pachler, Holck (14) } & 2008 & Two & One (Case 1) & Flat polypoid lesion \\
\hline & & & One (Case 2) & Plaque-like lesion \\
\hline Rubio et al. (15) & 2010 & One & Three & One dome, one plaque-like lesion, one, an histological finding \\
\hline Coyne (16) & 2012 & One & One & Irregular sessile polyp \\
\hline Puppa, Molaro (17) & 2012 & One & One & Raised plaque \\
\hline Yamada, et al. (18) & 2012 & One & One & Polypoid lesion \\
\hline Rubio, Befrits, Ericsson (19) & 2013 & One & One & Polypoid lesion \\
\hline Yamada, Sekine, Matsuda (20) & 2013 & One & One & Sessile elevated lesion \\
\hline Kannuna, Rubio et al. (21) & 2015 & One & One & Sessile mass \\
\hline Rubio, Schmidt (cfr. Figure 1) & 2016 & One & One & Sessile villous polyp \\
\hline
\end{tabular}

worldwide, evolve from the GALT-free mucosa through adenoma-carcinoma sequence (5) and the serrated pathway (6). In contrast, CRCs arising in GALT mucosa are very rare. In 1954, Cuthbert Dukes described in patients with ulcerative colitis a lesion in the submucosa characterized by "misplaced" colonic epithelium surrounded by nodular lymphoid tissue (7). Dukes' description corresponds to that of GALT mucosa. He believed that the "misplaced" epithelium was the result of mucosal repair following regeneration of a mucosal ulcer and that the epithelium detached and buried in the submucosal would encourage cancer development (7). Searching for a confirmation of Dukes' hypothesis we reported the first case of GALT carcinoma in the colon in 1984 (8).

Based on the presence of a circumscribed elevation in the colorectal mucosa, GALT carcinomas have been also referred to as dome carcinomas (DCs).

The purpose of this communication was to review the descriptions of the mucosa covering GALT-CRCs.

\section{Materials and Methods}

The narratives of the architecture of the luminal mucosa given in the pathological reports in 21 GALT-CRCs were reviewed.

\section{Results}

Results of the review of the pathological reports in 20 GALTCRCs reported in the literature, as well as in a recent case of GALT-CRC found in a colectomy specimen (Figure 1), are given in Table I. The results revealed that three of the 21

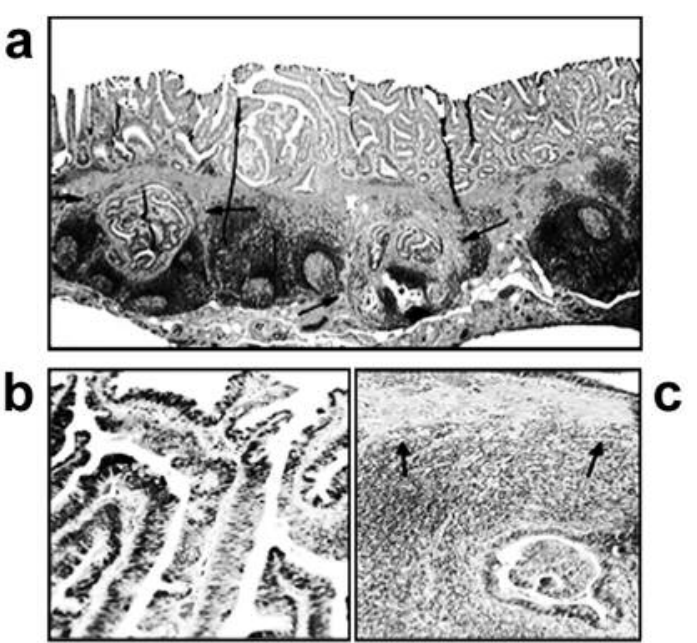

Figure 1. GALT carcinoma covered by a villous adenoma. a. GALT carcinoma showing adenocarcinoma islands in the submucosal (at arrows) surrounded by lymphoid tissue. On top, sessile villous adenoma $(H \& E$ staining, magnification $\times 2) . b$. Detail from the sessile villous adenoma with high-grade dysplasia ( $H \& E$ staining, magnification $\times 20)$. c. Detail from one adenocarcinoma island in the submucosa surrounded by lymphoid tissue. Muscularis mucosae at arrows (H\&E staining, magnification $\times 10$ ).

GALT-CRCs fulfilled the criteria of dome carcinoma. Of the remaining 18 GALT-CRCs, nine were described as polypoid lesions, five as plaque-like lesions, two as sessile lesions or mass, one as ulcerated and one as histological finding. 


\section{Discussion}

This study revealed that only $14.3 \%(n=3)$ of the 21 GALT carcinomas showed dome configurations. The remaining $85.7 \%(n=18)$ exhibited, at gross examination, structures other than dome shapes ranging from polypoid lesions, plaque-like lesions, sessile polyps or lesions, sessile masses or ulcerated lesions to normal histology (Table I). Based on these results, it becomes apparent that by using "dome" in addressing carcinomas in the colorectal mucosa, many cases of GALT carcinomas will be overlooked. Superficial pinch biopsies may contain only dysplastic epithelium from an adenoma concealing a GALT-CRC in the submucosa. Another drawback of using the "dome" nomenclature is that dome-like configurations may be detected in small metastatic tumors in the submucosa or in small carcinomas not arising in GALT mucosa.

Conversely, by using "GALT carcinoma" in addressing these neoplasias, all cases of GALT-CRCs will be included in that diagnosis.

\section{Conflicts of Interest}

None.

\section{References}

1 Neutra M, Mantis N and Kraehenbuhl JP: Collaboration of epithelial cells with organized mucosal lymphoid tissues. Nature Immunol 2: 1004-1009, 2001.

2 O'Leary AD and Sweeney EC: Lymphoglandular complexes of the normal colon: histochemistry and immunohistochemistry. Ir J Med Sci 156: 142-148, 1987.

3 Nascimbeni R, Di Fabio F, Di Betta E, Mariani P, Fisogni S and Villanacci V: Morphology of colorectal lymphoid aggregates in cancer, diverticular and inflammatory bowel diseases. Mod Pathol 18: 681-685, 2005.

4 Rubio CA, Ásmundsson J, Silva P, Illies C, Hartman J and Kis L: Lymphoid aggregates in Crohn's colitis and mucosal immunity. Virchows Arch 463: 637-642, 2013.

5 Jackman RJ and Mayo CW: The adenoma-carcinoma sequence in cancer of the colon. Surg Gynecol Obstet 93: 327-330, 1951.

6 Jass JR: Serrated route to colorectal cancer: back street or super highway? J Pathol 193: 283-285, 2001.

7 Dukes CE: The surgical pathology of ulcerative colitis. Ann R Coll Surg Engl 14: 389-400, 1954.
8 Rubio CA: Ectopic colonic mucosa in ulcerative colitis and in Crohn's disease of the colon. Dis Colon Rectum 27: 182-186, 1984.

9 De Petris G, Lev R, Quirk D, Ferbend P, Butmarc J and Elenitoba-Johnson K: Lymphoepithelioma-like carcinoma of the colon in a patient with Hereditary Nonpolyposis Colorectal Cancer. Arch Pathol Lab Med 123: 720-724, 1999.

10 Jass J, Constable L, Sutherland R, Winterford J, Walsh M, Young $\mathrm{J}$ and Leggett B: Adenocarcinoma of colon differentiating as dome epithelium of gut-associated lymphoid tissue. Histopathology 36: 116-120, 2000.

11 Clouston AD, Clouston DR and Jass JR: Adenocarcinoma of colon differentiating as dome epithelium of gut-associated lymphoid tissue. Histopathology 37: 567-569, 2000.

12 Rubio CA and Talbot I: Lymphoid-associated neoplasia in herniated colonic mucosa. Histopathology 40: 577-579, 2002.

13 Stewart C, Hillery S, Newman N, Platell C and G Ryan: Dometype carcinoma of the colon. Histopathology 53: 231-233, 2008.

14 Asmussen L, PachlerJ and Holck S: Colorectal carcinoma with dome-like phenotype: an under-recognised subset of colorectal carcinoma? J Clin Pathol 61: 482-486, 2008.

15 Rubio CA, Lindh C, Björk J, Törnblom $\mathrm{H}$ and Befrits R: Protruding and non-protruding colon carcinomas originating in gut-associated lymphoid tissue. Anticancer Res 30: 3019-3022, 2010.

16 Coyne JD: Dome-type colorectal carcinoma: a case report and review of the literature. Colorectal Dis 14: e360-362, 2012.

17 Puppa G and Molaro M: Dome-type: a distinctive variant of colonic adenocarcinoma. Case Rep Pathol 12: 28406, 2012.

18 Yamada M, Sekine S, Matsuda T, Yoshida M, Taniguchi H, Kushima R, Sakamoto T, Nakajima T, Saito Y and Akasu T: Dome-type carcinoma of the colon; a rare variant of adenocarcinoma resembling a submucosal tumor: a case report. BMC Gastroenterol 12: 21-32, 2012.

19 Rubio CA, Befrits R and Ericsson J: Carcinoma in gut-associated lymphoid tissue in ulcerative colitis: Case report and review of literature. World J Gastrointest Endosc 5: 293-296, 2013.

20 Yamada M, Sekine S and Matsuda T: Dome-type carcinoma of the colon masquerading a submucosal tumor. Clin Gastroenterol Hepatol 11: A30, 2013.

21 Kannuna H, Rubio CA, Silverio PC, Girardin M, Goossens N, Rubbia-Brandt L and Puppa G: DOME/GALT type adenocarcimoma of the colon: a case report, literature review and a unified phenotypic categorization. Diagn Pathol 10: 92-96, 2015.

Received August 1, 2016

Revised August 17, 2016

Accepted August 18, 2016 